\title{
Minimal Nutritional Requirements of Bacillus sphaericus NCTC 9602 and 26 other Strains of this Species: the Majority Grow and Sporulate with Acetate as Sole Major Source of Carbon
}

\author{
By P. J. WHITE* AND HARBHAJAN K. LOTAY $\dagger$ \\ Department of Microbiology, The University, Western Bank, Sheffield S10 2TN
}

(Received 15 October 1979)

\begin{abstract}
Bacillus sphaericus NCTC 9602 grew and sporulated in a simple chemically defined minimal medium containing only $\mathrm{KH}_{2} \mathrm{PO}_{4} / \mathrm{Na}_{2} \mathrm{HPO}_{4}$ buffer, $\mathrm{pH} 7 \cdot 2,15 \mathrm{~mm}$-ammonium sulphate, inorganic salts and sodium acetate (as sole source of carbon); no vitamins were needed. The organisms contained the characteristic enzymes of the glyoxylate cycle (isocitrate lyase and malate synthase) but lacked pyruvate dehydrogenase. Isocitrate dehydrogenase and 2-oxoglutarate dehydrogenase were both present.

The minimal nutritional requirements of 26 other strains of $B$. sphaericus were investigated. Three of these (including the type culture) grew and sporulated in the above minimal medium, and a further 13 strains grew and sporulated when only biotin and thiamin were added. Two more strains grew in the minimal medium plus these vitamins and glutamic acid. Four of the remaining strains needed several amino acids, but not acetate, and four other strains required a purine as well as amino acids.
\end{abstract}

\section{INTRODUCTION}

Bacillus sphaericus is a rod-shaped, spore-forming, strictly aerobic bacterium; its spores are spherical and cause obvious terminal swelling of the sporangium. Closely related species are Bacillus pasteurii, B. fusiformis, B. loehnisii and B. rotans; the last three species are now usually regarded as variants of $B$. sphaericus (Gordon et al., 1973). These five species are among the most numerous representatives of the genus Bacillus found in soils (Buchanan \& Gibbons, 1974).

Powell \& Strange (1957) examined three strains of B. sphaericus (including NCTC 9602) and found that the vegetative walls of all contained lysine (and aspartate) rather than diaminopimelate, though the peptidoglycan of the spore did contain diaminopimelate. In recent years, the biochemistry of the wall and of spore formation in B. sphaericus 9602 has been extensively studied (e.g. Hungerer \& Tipper, 1969; Tipper \& Linnett, 1976), but the organisms have always been grown in an undefined complex medium. The present work began with an attempt to grow this strain in a chemically defined medium, as a preliminary to a study of the diaminopimelate in its spores.

Relatively little work has been done on the nutrition of $B$. sphaericus. Knight \& Proom (1950) found that none of 19 strains of $B$. sphaericus grew in a simple chemically defined medium with glucose, ammonium, phosphate and sulphate ions as principal nutrients. All grew when this medium was supplemented with acid-hydrolysed casein, biotin and thiamin. The acid-hydrolysed casein could be replaced by a mixture of 14 amino acids for growth of all but one of the strains, or by a mixture of only 7 amino acids for growth of most of

$\dagger$ Present address: Department of Pathology, Chase Farm Hospital, The Ridgeway, Enfield, Middlesex. 
the strains. Bornside \& Kallio (1956) confirmed that amino acids plus thiamin or plus thiamin and biotin were needed by six strains of $B$. sphaericus, whereas four strains of $B$. loehnisii required only amino acids. Iyer \& Kallio (1958) described one strain of B. sphaericus that grew with $N$-methylurea as sole major source of carbon, though yeast extract was also present in the medium. Chan et al. (1973) described a minimal defined medium (glucose, glutamate, salts and EDTA) which supported abundant growth of the one strain of B. sphaericus that they examined. Hastie \& Brinton (1979) grew B. sphaericus 9602 in a defined medium (with amino acids and vitamins) similar to that of Knight \& Proom (1950).

The minimal medium that has now been devised for B. sphaericus 9602 contains no vitamins and only acetate as carbon source. The type culture (B. sphaericus NCIB 9370) also grows in this simple medium. The study has been extended to numerous other strains of $B$. sphaericus to establish whether all are less exacting nutritionally than had previously been supposed.

\section{METHODS}

Organisms. The strains of Bacillus sphaericus used in this study are listed in Table 1. Strain 9602 was from the NCTC and strains $8216,8217,8218$ and 9370 from the NCIB. All other strains were provided by Dr Ruth Gordon (Rutgers University, N.J., U.S.A.). This collection of strains is the same (apart from the addition of NCTC 9602) as that used in a previous general survey of the properties of the species (Gordon et al., 1973). All strains were maintained on slopes of nutrient agar which were incubated at $30^{\circ} \mathrm{C}$ and then stored at $2^{\circ} \mathrm{C}$.

Media. The defined medium A (White, 1972) was modified by using sodium acetate. $3 \mathrm{H}_{2} \mathrm{O}\left(5 \mathrm{~g} \mathrm{l}^{-1}\right)$ as principal carbon source in place of glycerol or glucose; trisodium citrate. $2 \mathrm{H}_{2} \mathrm{O}\left(20 \mathrm{mg} \mathrm{l}^{-1}\right)$ was also added unless otherwise stated. This medium was called A3. All components of the medium (apart from salts of $\mathrm{Mg}^{2+}, \mathrm{Fe}^{2+}$ and $\mathrm{Mn}^{2+}$ ) were combined before autoclaving, except where stated otherwise. Sodium acetate and glutamic acid were always added as solutions, adjusted to $\mathrm{pH} 7$. Solid medium contained $2 \%(\mathrm{w} / \mathrm{v})$ Difco agar and was dried at $37^{\circ} \mathrm{C}$ for $24 \mathrm{~h}$ to prevent spreading of surface growth. Various supplements of $\mathrm{L}$-amino acids were used, generally at the following concentrations $\left(\mathrm{mg}^{-1}\right)$ : Difco 'vitamin-free' Casamino acids (acid-hydrolysed casein), 5000; alanine, 40; arginine. $\mathrm{HCl}, 160$; aspartate, 50; asparagine, 40; cystine. $\mathrm{HCl}$, 250; glutamate, 500; glutamine, 40; glycine, 80; histidine. $\mathrm{HCl}, 160$; isoleucine, 40; leucine, 100 ; lysine. $\mathrm{HCl}, 50$; methionine, 80 ; phenylalanine, 100 ; proline, 30; serine, 40; threonine, 30; tryptophan, 100; tyrosine, 140 ; valine, 160 . Vitamin supplements were $\left(\mathrm{mg} \mathrm{1}^{-1}\right)$ : biotin, 0.002 ; thiamin, 10 ; pyridoxine, 10 ; pyridoxal, 10 ; pyridoxamine. $2 \mathrm{HCl}, 10$; nicotinic acid, 10 ; sodium pantothenate, 10 ; riboflavin, 10 ; calcium 5-formyltetrahydropteroylglutamate, $0 \cdot 01$. Adenine and guanine were each added to give $20 \mathrm{mg} \mathrm{l}^{-1}$.

Growth. In liquid cultures, growth was measured turbidimetrically in an EEL colorimeter, as described by White (1972). A reading of 1.0 was equivalent to $0.4 \mathrm{mg} \mathrm{dry} \mathrm{wt} \mathrm{ml}^{-1}\left(1 \times 10^{9}\right.$ organisms $\left.\mathrm{ml}^{-1}\right)$.

Tests for nutritional requirements. Strains were first screened on solid medium A3 plus biotin and thiamin, at both 25 and $30^{\circ} \mathrm{C}$. Strains that grew well in this first test were next examined on medium A3 without vitamins, and sometimes with either vitamin added singly. Strains that failed to grow in the first test after $48 \mathrm{~h}$ were examined on medium A3 containing Casamino acids, complete vitamin mixture, adenine and guanine, a medium on which all the more exacting strains grew. Progressive omissions were then made to find the minimal requirements. These tests were done in liquid medium $(50 \mathrm{ml})$ in shaken $250 \mathrm{ml}$ flasks incubated at $30^{\circ} \mathrm{C}$. With every strain, growth at $30^{\circ} \mathrm{C}$ was faster (on complex or defined media) than at $25^{\circ} \mathrm{C}$, while growth at $37^{\circ} \mathrm{C}$ was always much poorer.

Sporulation. Strains that grew vegetatively on medium A3 plus only biotin and thiamin were tested for sporulation on the same solid medium supplemented with $1 \mathrm{~mm}-\mathrm{CaCl}_{2}$ (added as a sterile solution to the autoclaved medium). Cultures were incubated at $30^{\circ} \mathrm{C}$ and examined microscopically at intervals. Sporulating organisms were suspended in water, heated at $60^{\circ} \mathrm{C}$ for $30 \mathrm{~min}$, and then plated on nutrient agar and incubated at $30^{\circ} \mathrm{C}$ overnight. The appearance of colonies of $B$. sphaericus confirmed that heat-stable spores had been formed in the simple defined medium.

Enzymic assays. Bacillus sphaericus 9602 was grown at $30^{\circ} \mathrm{C}$ on a mechanical shaker in liquid medium A3 $(500 \mathrm{ml}$ per 21 flask). Organisms were harvested late in the exponential phase of growth, when few (if any) spores were visible, and were washed and resuspended in the buffer that was appropriate for the enzymic assay in which the extract was subsequently to be used. Extracts were made at $2{ }^{\circ} \mathrm{C}$ by passing the suspended organisms through the pressure cell of Milner et al. (1950), operated at $140 \mathrm{MPa}$, and then removing the debris by centrifuging at $20000 \mathrm{~g}$ for $20 \mathrm{~min}$ at $2^{\circ} \mathrm{C}$. Protein in the extracts was assayed by the Lowry method, with bovine serum albumin as standard. 
Enzymic activities in the extracts were measured at $30^{\circ} \mathrm{C}$. Pyruvate dehydrogenase complex (overall reaction) was assayed by recording the anaerobic (see White, 1979) pyruvate-dependent reduction of $\mathrm{NAD}^{+}$ in a reaction mixture similar to that of Guest \& Creaghan (1973); 2-oxoglutarate dehydrogenase complex (overall reaction) was assayed similarly. Pyruvate dehydrogenase E1 (EC 1.2.4.1) was assayed spectrophotometrically at $420 \mathrm{~nm}$ and $\mathrm{pH} 6.3$ or 7.0 with ferricyanide as electron acceptor (Hager \& Kornberg, 1961), and 2-oxoglutarate dehydrogenase E1 (EC 1.2.4.2) was assayed similarly. Isocitrate lyase (EC 4.1.3.1) was assayed as described by Kornberg (1965), with the dinitrophenylhydrazones of glyoxylic acid identified as described by Salem et al. (1973). Malate synthase (EC 4.1.3.2) was assayed by the method of Cox \& Quayle (1976). Isocitrate dehydrogenase (EC 1.1.1.41) was assayed by the method of Plaut (1962). Glutamate dehydrogenase (EC 1.4.1.4) and glutamate synthase (EC 1.4.1.13) were assayed anaerobically at $\mathrm{pH} 7.6$ as described by Meers et al. (1970) and White (1979) with NADPH as cofactor.

Peptidoglycans of walls and spores of B. sphaericus 9602 . Organisms were grown at $30^{\circ} \mathrm{C}$ in medium $\mathrm{A} 3$ as described above, and walls were isolated from exponential phase bacteria by the procedure of Day \& White (1977). A suspension of walls $\left(10 \mathrm{mg} \mathrm{ml}^{-1}\right)$ in $0.1 \mathrm{M}$-ammonium acetate, $\mathrm{pH} 6.5$ was incubated with lysozyme $\left(100 \mu \mathrm{g} \mathrm{ml}^{-1}\right)$ at $37^{\circ} \mathrm{C}$ for $1 \mathrm{~h}$. Insoluble material was removed by centrifuging; the supernatant liquid was mixed with an equal volume of $11.6 \mathrm{M}-\mathrm{HCl}$ and heated at $105^{\circ} \mathrm{C}$ for $18 \mathrm{~h}$ or for $48 \mathrm{~h}$ in sealed tubes. The hydrolysates were dried in a desiccator over $\mathrm{NaOH}$ pellets, and acid was removed by repeated addition and evaporation of water.

Spores were obtained (after incubation at $30^{\circ} \mathrm{C}$ for $3 \mathrm{~d}$ ) from cultures in medium $\mathrm{A} 3$ plus $1 \mathrm{~mm}-\mathrm{CaCl}_{2}$, grown as above. The mixture of spores and organisms was harvested by centrifuging and suspended in $0 \cdot 1 \mathrm{M}-\mathrm{Na}_{2} \mathrm{HPO}_{4} / \mathrm{NaH}_{2} \mathrm{PO}_{4}$ buffer, $\mathrm{pH} 6 \cdot 5$. The suspension was passed through a pressure cell (Milner et al., 1950 ) at $100 \mathrm{MPa}$ (to break vegetative organisms) and then centrifuged at $20000 \mathrm{~g}$ for $15 \mathrm{~min}$ at $2{ }^{\circ} \mathrm{C}$. The pellet (spores and debris) was resuspended in $0 \cdot 1 \mathrm{M}-\mathrm{Na}_{2} \mathrm{HPO}_{4} / \mathrm{NaH}_{2} \mathrm{PO}_{4}$ buffer, $\mathrm{pH} 6.5$, autoclaved at $121{ }^{\circ} \mathrm{C}$ for $30 \mathrm{~min}$ (to inactivate lytic enzymes) and then incubated with lysozyme $\left(100 \mu \mathrm{g} \mathrm{ml}^{-1}\right)$ for $1 \mathrm{~h}$ at $37^{\circ} \mathrm{C}$. The solid residue (mostly spores) was collected by centrifuging and the spores were isolated by solvent partition (Sacks \& Alderton, 1961).

Spores were broken by shaking with glass beads and then incubated at $37{ }^{\circ} \mathrm{C}$ with ribonuclease followed by trypsin, both in $0.05 \mathrm{M}$-Tris/ $\mathrm{HCl}$ buffer, $\mathrm{pH} \mathrm{7.6}$. The resulting spore integuments were resuspended in $0.1 \mathrm{M}$-ammonium acetate, $\mathrm{pH} 6.5$ and incubated at $37^{\circ} \mathrm{C}$ overnight with lysozyme $\left(300 \mu \mathrm{g} \mathrm{ml}^{-1}\right)$ in the presence of toluene. The material digested by lysozyme (i.e. cortical peptidoglycan) was hydrolysed at $105^{\circ} \mathrm{C}$ for $18 \mathrm{~h}$ with $6 \mathrm{M}-\mathrm{HCl}$ and then dried repeatedly, as described above.

Amino acids in each hydrolysate were separated by paper chromatography with the solvent methanol/ pyridine $/ 11.6 \mathrm{M}-\mathrm{HCl} /$ water $(80: 10: 2 \cdot 5: 17 \cdot 5$, by vol.; Rhuland et al., 1955) and spots were detected with ninhydrin. Quantitative measurements of amino acids were made with an autoanalyser, and by the appropriate methods of Work (1957).

\section{RESULTS}

\section{Nutritional requirements of 27 strains of $B$. sphaericus}

Spores of B. sphaericus 9602 were obtained from complex medium, as described by Hungerer \& Tipper (1969), and were used as inoculum throughout the initial tests on solid media. Medium A salts plus only sodium acetate. $3 \mathrm{H}_{2} \mathrm{O}\left(5 \mathrm{~g} \mathrm{l}^{-1}\right)$ and L-glutamate or Laspartate (each $1 \mathrm{~g} \mathrm{l}^{-1}$ ) proved adequate to support good vegetative growth in liquid culture from heat-shocked spores $\left(80^{\circ} \mathrm{C}\right.$ for $\left.30 \mathrm{~min}\right)$. When vegetative organisms were used as inoculum the glutamate could be omitted, although growth was then slower. Increasing the concentration of acetate did not improve growth. Neither spores nor vegetative organisms grew in minimal salts plus L-glutamate ( 1 to $5 \mathrm{~g}^{-1}$ ) when acetate was omitted. Growth with butyrate or DL- $\beta$-hydroxybutyrate $\left(\mathrm{Na}^{+}\right.$salts; $\left.3 \mathrm{~g} \mathrm{l}^{-1}\right)$ as sole carbon source was slower but the final yield of organisms was higher than with acetate. Omission of citrate from medium A3 had no apparent effect on growth.

The unexpectedly simple requirements of strain 9602 prompted a survey of other strains. The minimal nutritional requirements of 27 separate strains of $B$. sphaericus are shown in Table 1. There are 31 strains listed, but some (ATCC 4978 and NRS 633; ATCC 7054, ATCC 12300 and NRS 866; ATCC 12123 and NRS T111) are supposedly identical strains, obtained from different sources (Gordon et al., 1973). 


\section{Table 2. Minimal nutritional requirements of the more exacting strains of B. sphaericus}

Procedures for determining the minimal requirements are described in Methods. Numbers in parentheses are the concentrations (in $\mathrm{mg}^{-1}$ ) used in the minimal media, and were the same throughout for a given substance. All amino acids were L-isomers. Addition of the substances shown in square brackets slightly stimulated growth.

Strain

Minimal requirements in medium A salts (+ citrate)

NCIB 8216 Alanine (350); asparagine (40); glutamate (1000); methionine (100); guanine (20); thiamin (10)

NCIB 8217 Alanine; glutamate; methionine; phenylalanine (100); adenine (20); guanine

NCIB 8218 Alanine; asparagine; glutamate; serine (200); guanine; thiamin; pyridoxine. $\mathrm{HCl}(20)$

ATCC $4978^{*}$
NRS $633^{*}$ Casamino acids (5000); guanine

ATCC 7063 Casamino acids [sodium acetate. $3 \mathrm{H}_{2} \mathrm{O}(5000)$ ]

NRS 592 Casamino acids; biotin (0.002); thiamin

NRS 672 Casamino acids [acetate]

NRS 1223 Casamino acids; biotin; thiamin

* Supposedly identical strains that have different numbers.

\section{Other properties of B. sphaericus 9602}

In medium A3 the doubling time during exponential growth was approximately $2 \mathrm{~h}$. Growth stopped at a dry weight equivalent of about $1.0 \mathrm{mg} \mathrm{ml}^{-1}$; the final $\mathrm{pH}$ value of the medium was $8 \cdot 0$ to $8 \cdot 5$. Neither the vegetative organisms nor the spores could be distinguished (by phase contrast microscopy) from those grown in complex media - the organisms (rods, about $5 \mu \mathrm{m}$ long and very motile) occurred singly, and produced spherical, terminal spores.

Various other carbon sources [ethanol, glycollate, glycine, L-serine, $N$-methylurea, DL-lactate, pyruvate, 2-oxoglutarate, glucose, glycerol, succinate, fumarate, L-malate, propionate $\left(\mathrm{Na}^{+}\right.$salts, where appropriate)] were tested (at concentrations between 1 and $10 \mathrm{~g}^{-1}$ ) as replacements for acetate in minimal salts medium, but none supported growth. When added with a sub-optimal concentration of sodium acetate. $3 \mathrm{H}_{2} \mathrm{O}\left(1 \mathrm{~g} \mathrm{l}^{-1}\right)$ none of the above compounds (added singly) caused quicker or heavier growth. Addition of DL-lipoic acid ( 2 to $10 \mu \mathrm{g} \mathrm{l}^{-1}$ ) together with pyruvate (which was added to the autoclaved medium as a sterile-filtered solution) did not promote growth without acetate.

Extracts were made (see Methods) and various enzymes were assayed (Table 3). The characteristic enzymes of the glyoxylate cycle (isocitrate lyase and malate synthase) were found. Because isocitrate dehydrogenase was also present, it was necessary to show (as was done) that the product formed in the assay for isocitrate lyase was indeed glyoxylate (by identification of its dinitrophenylhydrazones) rather than 2-oxoglutarate. The relatively high activity of glutamate dehydrogenase and absence of glutamate synthase suggest that the former enzyme may be the means of assimilation of ammonia. Since the enzymes needed for synthesis of glutamate are present with good activity in the vegetative organisms grown on acetate alone, it is surprising that addition of glutamate should stimulate growth, especially as this amino acid (15 mM) did not support growth when it was sole source of nitrogen, in medium $\mathrm{A} 3$ from which $\left(\mathrm{NH}_{4}\right)_{2} \mathrm{SO}_{4}$ was omitted and replaced by $\mathrm{Na}_{2} \mathrm{SO}_{4}$. $10 \mathrm{H}_{2} \mathrm{O}\left(4 \mathrm{~g} \mathrm{l}^{-1}\right)$.

Vegetative walls were isolated and hydrolysed as described in Methods. No diaminopimelate was found in the hydrolysate $(48 \mathrm{~h}, 6 \mathrm{M}-\mathrm{HCl})$, which contained as principal components [ $\mu \mathrm{mol}(\mathrm{mg} \text { wall })^{-1}$ ]: alanine, 0.75 ; glutamate, 0.55 ; aspartate, $0.62 ;$ lysine, 0.51 . The hydrolysate of peptidoglycan from the spore cortex contained diaminopimelate as well as lysine, though in relatively small quantities (molar proportions: alanine, 1.36; glutamate, $1 \cdot 00$; aspartate, $1 \cdot 22$; diaminopimelate, 0.34 ; lysine, $0 \cdot 45$ ). 
Table 3. Enzymic activities in B. sphaericus 9602

Organisms were grown and extracts were made as described in Methods. Procedures for the various assays are described in Methods. The pH values, substrate concentrations etc. used in the assays are not necessarily optimal for the enzymes from $B$. sphaericus. All assays that showed low activities were repeated at least once with another fresh extract.

Enzyme

Isocitrate lyase

Malate synthase

Isocitrate dehydrogenase

2-Oxoglutarate dehydrogenase (overall reaction)

2-Oxoglutarate dehydrogenase E1

Pyruvate dehydrogenase (overall reaction)

Pyruvate dehydrogenase E1

Glutamate dehydrogenase

Glutamate synthase
Activity [nmol $\left.\mathrm{min}^{-1}(\mathrm{mg} \text { protein })^{-1}\right]$

350

97

55

4

34 (pH 6.3)

$0(\mathrm{pH} 7 \cdot 0)$

0

0 (pH 6.3)

400

0 (pH 7.0)

0
$44 *$

$192 *(\mathrm{pH} 6 \cdot 3)$

41 *

$30 *(\mathrm{pH} \mathrm{6.3)}$

$15 *(\mathrm{pH} 7 \cdot 0$ )

* Activity in an extract of Escherichia coli ATCC 9637 which was used to check that the assay system was functioning properly. The organisms were grown in medium $A 3$ (at $37^{\circ} \mathrm{C}$ ) and extracts were prepared as for B. sphaericus.

\section{DISCUSSION}

Bacillus sphaericus 9602 grew readily and sporulated in a simple chemically defined medium with acetate as sole source of carbon. The organisms were indistinguishable morphologically and in the composition of their peptidoglycans (vegetative and spore) from bacteria grown in complex media. Anaplerotic synthesis presumably occurs by means of the glyoxylate cycle. If this is so, then the normal tricarboxylic acid cycle should also be functional, since both isocitrate dehydrogenase and 2-oxoglutarate dehydrogenase were present; other necessary enzymes are common to both cycles.

The absence of pyruvate dehydrogenase explains the nutritional requirement for acetate. Substrates that give rise to acetate by only this metabolic route (e.g. glucose, succinate) are unable to provide all the necessary intermediates for biosynthesis. However, it is surprising that such substrates do not increase the rate or extent of growth when a limited supply of acetate is available. A compound such as succinate would be expected to furnish reducing power, ATP and biosynthetic intermediates, and so spare the requirement for acetate. Of the compounds tested, glutamate or aspartate alone improved growth with acetate. Possibly the organisms are selectively permeable to these amino acids. Whether B. sphaericus 9602 is really a strict acetotroph has not been established, but no other single carbon source among the small number tested was found to support growth, other than butyrate and $\beta$-hydroxybutyrate from which acetate can be generated without pyruvate dehydrogenase.

Numerous other strains of $B$. sphaericus grew with acetate as sole major carbon source, though most also required thiamin and/or biotin. However, several strains were considerably more exacting, yet no distinctions can be made between these strains and those with simpler requirements on the basis of their other characteristics, as reported by Gordon et al. (1973). The most exacting strains used amino acids as sources of carbon. Whether the amino acids are also principal nitrogen sources has not been shown.

It must be emphasized that the defined media used in this study are minimal media. With nearly every strain, growth was faster and heavier on nutrient agar than on the solid defined media. Considerably more work would be needed to develop optimal defined media and growth conditions for every strain. 
Miss Lorna B. Young has given excellent technical assistance throughout this work. Preliminary experiments with B. sphaericus 9602 were done by Dr Farangis Saleh. Dr Ruth Gordon has very generously provided many strains and much information. Amino acid analyses were done in the Department of Biochemistry, University of Sheffield.

\section{REFERENCES}

Bornside, G. H. \& Kallio, R. E. (1956). Ureahydrolysing bacilli II. Nutritional profiles. Journal of Bacteriology 71, 655-660.

Buchanan, R. E. \& Gibbons, N. E. (editors) (1974). Bergey's Manual of Determinative Bacteriology, 8th edn, pp. 542-543. Baltimore: Williams \& Wilkins.

Chan, E. C. S., Rutter, P. J. \& Willis, A. (1973). Abundant growth and sporulation of Bacillus sphaericus NCA Hoop 1-A-2 in a chemically defined medium. Canadian Journal of Microbiology 19, 151-154.

Cox, R. B. \& Quayle, J. R. (1976). Synthesis and hydrolysis of malylcoenzyme A by Pseudomonas AM1: an apparent malate synthase activity. Journal of General Microbiology 95, 121-133.

DAY, A. \& WhITE, P. J. (1977). Enzymic assays for isomers of 2,6-diaminopimelic acid in walls of Bacillus cereus and Bacillus megaterium. Biochemical Journal 161, 677-685.

Gordon, R. E., Haynes, W. C. \& Pang, C. H.-N. (1973). The Genus Bacillus. Agriculture Handbook No. 427. Washington: Agricultural Research Service, U.S. Department of Agriculture.

Guest, J. R. \& Creaghan, I. T. (1973). Geneprotein relationships of the $\alpha$-keto acid dehydrogenase complexes of Escherichia coli K12: isolation and characterization of lipoamide dehydrogenase mutants. Journal of General Microbiology 75, 197-210.

Hager, L. P. \& Kornberg, H. L. (1961). On the mechanism of $\alpha$-oxoglutarate oxidation in Escherichia coli. Biochemical Journal 78, 194-198.

Hastie, A. T. \& Brinton, C. C. (1979). Isolation, characterization, and in vitro assembly of the tetragonally arrayed layer of Bacillus sphaericus. Journal of Bacteriology 138, 999-1009.

Hungerer, K. D. \& TipPer, D. J. (1969). Cell wall polymers of Bacillus sphaericus 9602 . I. Structure of the vegetative cell wall peptidoglycan. Biochemistry 8, 3577-3587.

IYeR, S. N. \& Kallio, R. E. (1958). Bacterial degradation of methylurea. Archives of Biochemistry and Biophysics 76, 295-305.

Knight, B. C. J. G. \& Proom, H. (1950). A comparative survey of the nutrition and physiology of mesophilic species in the genus Bacillus. Journal of General Microbiology 4, 508-538.

KorNBERG, H. L. (1965). Control of biosynthesis from $\mathrm{C}_{2}$-compounds. Colloques internationaux $d u$ Centre National de la Recherche Scientifique 124, 193-207.

Meers, J. L., Tempest, D. W. \& Brown, C. M. (1970). 'Glutamine (amide): 2-oxoglutarate amino transferase oxido-reductase (NADP)', an enzyme involved in the synthesis of glutamate by some bacteria. Journal of General Microbiology 64, 187-194.

Milner, H. W., Lawrence, N. S. \& French, C. S. (1950). Colloidal dispersion of chloroplast material. Science 111, 633-634.

Plaut, G. W. E. (1962). Isocitric dehydrogenase (TPN-linked) from pig heart (revised procedure). Methods in Enzymology 5, 645-651.

Powell, J. F. \& Strange, R. E. (1957). $\alpha \in$-Diaminopimelic acid metabolism and sporulation in Bacillus sphaericus. Biochemical Journal 65, 700708.

Rhuland, L. E., Work, E., Denman, R. F. \& HoARE, D. S. (1955). The behaviour of isomers of $\alpha, \epsilon$-diaminopimelic acid on paper chromatograms. Journal of the American Chemical Society 77, 4844-4846.

SACKs, L. E. \& Alderton, G. (1961). Behaviour of bacterial spores in aqueous polymer two-phase systems. Journal of Bacteriology 82, 331-341.

Salem, A. R., Hacking, A.J. \& Quayle, J. R. (1973). Cleavage of malyl-coenzyme $A$ into acetylcoenzyme A and glyoxylate by Pseudomonas AM1 and other $\mathrm{C}_{1}$-unit-utilizing bacteria. Biochemical Journal 136, 89-96.

TiPPER, D. J. \& LinneTt, P. E. (1976). Distribution of peptidoglycan synthetase activities between sporangia and forespores in sporulating cells of Bacillus sphaericus. Journal of Bacteriology 126, 213-221.

White, P. J. (1972). The nutrition of Bacillus megaterium and Bacillus cereus. Journal of General Microbiology 71, 505-514.

White, P. J. (1979). Effects of D-glutamate on enzymes of ammonia assimilation in Bacillus megaterium NCIB 7581. Journal of General Microbiology 114, 159-168.

Work, E. (1957). Reaction of ninhydrin in acid solution with straight-chain amino acids containing two amino groups and its application to the estimation of $\alpha \epsilon$-diaminopimelic acid. Biochemical Journal 67, 416-423. 